\title{
Consensus Reports
}

Effective January 2010, prior reports of the types listed below were renamed "consensus reports."

\section{EXPERT COMMITTEE REPORTS}

International Expert Committee Report on the Role of the AlC Assay in the Diagnosis of Diabetes

International Expert Committee

Diabetes Care 32:1327-1334, 2009

Follow-Up Report on the Diagnosis of Diabetes Mellitus

Expert Committee on the Diagnosis and Classification of Diabetes

Diabetes Care 26:3160-3167, 2003

\section{WORKGROUP REPORTS}

The Charcot Foot in Diabetes

Lee C. Rogers, Robert G. Frykberg, David G. Armstrong, Andrew J.M. Boulton, Michael Edmonds, Georges Ha Van, Agnes Hartemann, Frances Game, William Jeffcoate,Alexandra Jirkovska, Edward Jude, Stephan Morbach, William B. Morrison, Michael Pinzur, Dario Pitocco, Lee Sanders, Dane K. Wukich, and Luigi Uccioli Diabetes Care 34:2123-2129, 2011

Comprehensive Foot Examination and Risk Assessment: a Report of the Task Force of the Foot Care Interest Group of the American Diabetes Association, With Endorsement by the American Association of Clinical Endocrinologists

Andrew J.M. Boulton, David G. Armstrong, Stephen F. Albert, Robert G. Frykberg, Richard Hellman, M. Sue Kirkman, Lawrence A. Lavery, Joseph W. LeMaster, Joseph L. Mills, Sr., Michael J. Mueller, Peter Sheehan, and Dane K. Wukich Diabetes Care 31:1679-1685, 2008

American Diabetes Association Statement on Emergency and Disaster Preparedness: a Report of the Disaster Response Task Force

Disaster Response Task Force

Diabetes Care 30:2395-2398, 2007

\section{CONSENSUS REPORTS}

Diabetes and Cancer

Edward Giovannucci, David M. Harlan, Michael C. Archer, Richard M. Bergenstal, Susan M. Gapstur, Laurel A. Habel, Michael Pollak, Judith G. Regensteiner, and Douglas Yee
Diabetes Care 33:1674-1685, 2010

Medical Management of Hyperglycemia in Type 2 Diabetes: A Consensus Algorithm for the Initiation and Adjustment of Therapy: A Consensus Statement of the American Diabetes Association and the European Association for the Study of Diabetes

David M. Nathan, John B. Buse, Mayer B. Davidson, Ele Ferrannini, Rury R. Holman, Robert Sherwin, and Bernard Zinman

Diabetes Care 32:193-203, 2009

American Association of Clinical Endocrinologists and American Diabetes Association Consensus Statement on Inpatient Glycemic Control

Etie S. Moghissi, Mary T. Korytkowski, Monica DiNardo, Daniel Einhorn, Richard Hellman, Irl B. Hirsch, Silvio E. Inzucchi, Faramarz Ismail-Beigi, M. Sue Kirkman, and Guillermo E. Umpierrez Diabetes Care 32:1119-1131, 2009

Hyperglycemic Crises in Adult Patients With Diabetes

Abbas E. Kitabchi, Guillermo E. Umpierrez, John M. Miles, and Joseph N. Fisher Diabetes Care 32:1335-1343, 2009

How Do We Define Cure of Diabetes? John B. Buse, Sonia Caprio, William T. Cefalu, Antonio Ceriello, Stefano Del Prato, Silvio E. Inzucchi, Sue McLaughlin, Gordon L. Phillips II, R. Paul Robertson, Francesco Rubino, Richard Kahn, and M. Sue Kirkman.

Diabetes Care 32:2133-2135, 2009

Management of Hyperglycemia in Type 2 Diabetes: A Consensus Algorithm for the Initiation and Adjustment of Therapy: Update Regarding Thiazolidinediones: a Consensus Statement From the American Diabetes Association and the European Association for the Study of Diabetes

David M. Nathan, John B. Buse, Mayer B. Davidson, Ele Ferrannini, Rury R. Holman, Robert Sherwin, and Bernard Zinman Diabetes Care 31:173-175, 2008
Lipoprotein Management in Patients With Cardiometabolic Risk: Consensus Statement From the American Diabetes Association and the American College of Cardiology Foundation John D. Brunzell, Michael Davidson, Curt D. Furberg, Ronald B. Goldberg, Barbara V. Howard, James H. Stein, and Joseph L. Witztum

Diabetes Care 31:811-822, 2008

Managing Preexisting Diabetes for Pregnancy: Summary of Evidence and Consensus Recommendations for Care John L. Kitzmiller, Jennifer M. Block, Florence M. Brown, Patrick M. Catalano, Deborah L. Conway, Donald R. Coustan, Erica P. Gunderson, William H. Herman, Lisa D. Hoffman, Maribeth Inturrisi, Lois B. Jovanovic, Siri I. Kjos, Robert H. Knopp, Martin N. Montoro, Edward S. Ogata, Pathmaja Paramsothy, Diane M. Reader, Barak M. Rosenn, Alyce M. Thomas, and M. Sue Kirkman

Diabetes Care 31:1060-1079, 2008

Influence of Race, Ethnicity, and Culture on Childhood Obesity: Implications for Prevention and Treatment: A Consensus Statement of Shaping America's Health and the Obesity Society

Sonia Caprio, Stephen R. Daniels, Adam Drewnowski, Francine R. Kaufman, Lawrence A. Palinkas, Arlan L. Rosenbloom, and Jeffrey B. Schwimmer

Diabetes Care 31:2211-2221, 2008

Screening for Coronary Artery Disease in Patients With Diabetes

Jeroen J. Bax, Lawrence H. Young, Robert L. Frye, Robert O. Bonow, Helmut O. Steinberg, and Eugene J. Barrett Diabetes Care 30:2729-2736, 2007

Consensus Statement on the Worldwide Standardization of the Hemoglobin AlC Measurement: the American Diabetes Association, European Association for the Study of Diabetes, International Federation of Clinical Chemistry and Laboratory Medicine, and the International Diabetes Federation 
Consensus Committee

Diabetes Care 30:2399-2400, 2007

Use of Insulin Pump Therapy in the Pediatric Age-Group: Consensus Statement From the European Society for Paediatric Endocrinology, the Lawson Wilkins Pediatric Endocrine Society, and the International Society for Pediatric and Adolescent Diabetes, Endorsed by the American Diabetes Association and the European Association for the Study of Diabetes

Moshe Phillip, Tadej Battelino, Henry Rodriguez, Thomas Danne, Francine Kaufman for the Consensus forum participants

Diabetes Care 30:1653-1662, 2007
Waist Circumference and Cardiometabolic Risk: a Consensus Statement From Shaping America's Health: Association for Weight Management and Obesity Prevention; NAASO, The Obesity Society; the American Society for Nutrition; and the American Diabetes Association

Samuel Klein, David B. Allison, Steven B. Heymsfield, David E. Kelley, Rudolph L. Leibel, Cathy Nonas, and Richard Kahn Diabetes Care 30:1647-1652, 2007

Computer Modeling of Diabetes and Its Complications: a Report on the Fourth Mount Hood Challenge Meeting The Mount Hood 4 Modeling Group Diabetes Care 30:1638-1646, 2007
Impaired Fasting Glucose and Impaired Glucose Tolerance: Implications for Care

David M. Nathan, Mayer B. Davidson, Ralph A. DeFronzo, Robert J. Heine, Robert R. Henry, Richard Pratley, and Bernard Zinman

Diabetes Care 30:753-759, 2007

Diabetic Ketoacidosis in Infants, Children, and Adolescents: A Consensus Statement From the American Diabetes Association

Joseph Wolfsdorf, Nicole Glaser, and Mark A. Sperling

Diabetes Care 29:1150-1159, 2006 